\title{
Demonstration of generic handbooks for assisting in the management of contaminated food production systems and inhabited areas in Europe
}

\author{
A.F. NISBET ${ }^{1}$, K.G. ANDERSSON ${ }^{2}$, T. DURANOVA ${ }^{3}$
}

\begin{abstract}
Two handbooks have been developed in conjunction with a wide range of stakeholders that provide assistance in the management of contaminated food production systems and inhabited areas following a radiological incident. Emergency centres in Member States not involved in the development of these handbooks were invited to take part in demonstration activities to establish whether the handbooks would be useful for the purposes of contingency planning and accident management. Some eight centres took part. Emergency exercises or similar events based on scenarios involving contamination of the foodchain and inhabited areas were used. Feedback from all of the demonstrations was positive with constructive criticism given on how to improve the navigation, structure and format of the handbooks. All of the key improvements highlighted during the demonstrations were taken into account and included in version 2 of the handbooks. Two additional demonstrations took place in Denmark and Slovakia to investigate the appropriateness and applicability of a stakeholder participatory process when applying the handbooks. These stakeholders expressed their willingness to discuss the issues at stake from contamination of food production systems and inhabited areas and gave a clear commitment to continue the process.
\end{abstract}

\section{Introduction}

Two handbooks (Nisbet et al., 2006; Brown et al., 2007) to assist in the management of contaminated food production systems and inhabited areas following a radiological incident have been developed in conjunction with a wide range of stakeholders. These handbooks can be downloaded from the EURANOS (http://www.euranos.fzk.de) and Neris (http://www.eu-neris.net) websites. The handbooks are aimed at national and local authorities, emergency services, radiation protection experts, agriculture and food production sectors, industry and others who may be affected. The handbooks include management options for application in different phases of an incident. Sources of contamination considered

\footnotetext{
Radiation Protection Division, HPA, Didcot, UK.

RISØ National Laboratory, Denmark.

VUJE, Slovak Republic.
} 
in the handbooks include nuclear accidents, and radiological dispersion devices: the most relevant radionuclides are addressed. The handbooks can be used as a preparatory tool under non-crisis conditions to engage stakeholders and to develop local and regional plans. They can be applied as part of the decision-aiding process to develop a recovery strategy following an incident. In addition, the handbooks are useful for training purposes and during emergency exercises.

The EURANOS project provided an opportunity to demonstrate the usefulness and applicability of the two handbooks described above, for situations where food production systems and inhabited areas become contaminated as a result of a radiological emergency. The demonstration also provided an opportunity to investigate the value of engaging with stakeholders when customising and applying the handbook at national, regional or local levels.

\section{Methods}

Emergency centres not involved in the development of the handbooks were invited to participate in the demonstration. Emergency exercises or similar events based on scenarios involving contamination of the food chain or inhabited areas were used. Six demonstrations were carried out using the handbook for food production systems; five demonstrations took place with the handbook for inhabited areas. In addition two further demonstrations took place in Denmark and Slovakia to investigate the appropriateness and applicability of a stakeholder participatory process when applying the handbook for managing contaminated food production systems and inhabited areas, respectively.

An evaluation questionnaire was designed to facilitate the collection of information from the demonstrations in a systematic way. In addition, each of the participating organisations prepared a short report providing an assessment of the appropriateness/applicability of one or both of the handbooks. The report highlighted any difficulties experienced during the demonstration with some overall conclusions on applying the handbook(s) and where appropriate, of adopting a participatory approach involving stakeholders. The functions that were demonstrated are summarised in Table I.

\section{Results}

\subsection{Feedback on the handbooks}

Feedback from the evaluation questionnaires and from the reports for each of the demonstrations was collated. Positive feedback and points for improvement on the handbooks are summarised in Table II. 
TABLE I.

Functions that were investigated during demonstration of the handbooks or in adopting a participatory approach.

\begin{tabular}{|c|c|}
\hline Handbook & Participatory approach \\
\hline Installation & Support for the process \\
\hline $\begin{array}{l}\text { Format } \\
\text { - } \text { structure; } \\
\text { - user friendliness; } \\
\text { - appropriate level of detail. }\end{array}$ & Identification of wide range of stakeholders \\
\hline $\begin{array}{l}\text { Navigation } \\
\text { - interactive features; } \\
\text { - links. }\end{array}$ & $\begin{array}{l}\text { Engaging the stakeholders and their willingness to } \\
\text { participate }\end{array}$ \\
\hline $\begin{array}{l}\text { Content } \\
\text { - clarity; } \\
\text { - state-of-the-art; } \\
\text { - comprehensiveness. }\end{array}$ & $\begin{array}{l}\text { Openness in discussing issues raised by the handbooks } \\
\text { - raising awareness; } \\
\text { identifying specific problems. }\end{array}$ \\
\hline Scope & $\begin{array}{l}\text { Extending the process to developing a customised version } \\
\text { of the handbooks }\end{array}$ \\
\hline $\begin{array}{l}\text { Usefulness of various tools in identification of } \\
\text { management options } \\
\text { - selection tables; } \\
\text { - decision tree; } \\
\text { - look-up tables; } \\
\text { datasheets. }\end{array}$ & $\begin{array}{l}\text { Role of the stakeholders in the event of an incident, local, } \\
\text { national and regional level }\end{array}$ \\
\hline Suitability for customisation & Widening the process to a European network \\
\hline
\end{tabular}

A handbook users' group (HUG) was established in 2007 to provide a platform for maintaining the handbooks and to build a network of users for both the generic handbooks and any subsequently customised versions. A meeting of the HUG was organised to discuss feedback from the demonstration activities and to agree priorities for updating the handbooks. The following key improvements to the handbook for food production systems were agreed:

- Re-structuring the handbook to make navigation easier. Deleting some less relevant sections.

- Producing a "route map" or "quick guide" to aid navigation.

- Producing additional sets of 'grey scale' selection tables for colour-blind users and for printing purposes.

- Expanding the glossary.

- Including worked examples.

- Deleting decision trees and focusing on selection tables as the key decision aiding tool.

- Producing check-lists for planning in advance.

- Providing more information on monitoring and measurement strategies. 
TABLE II.

Feedback from the demonstrations of the handbooks.

\begin{tabular}{|c|c|}
\hline Function & Feedback \\
\hline Installation & No problems \\
\hline Format & $\begin{array}{l}\text { Positive } \\
\text { - systematically organised; } \\
\text { - user friendly after training and familiarisation. } \\
\text { Points for improvement } \\
\text { - difficult to interrogate the information and find specific information quickly; } \\
\text { - colour-coded selection tables not helpful if user is colour-blind; } \\
\text { - colour-coded selection tables not clear when printing in black and white. }\end{array}$ \\
\hline Navigation & $\begin{array}{l}\text { Positive } \\
- \text { generally easy to navigate. } \\
\text { Points for improvement } \\
\cdot \text { missing links between datasheets and decision trees. }\end{array}$ \\
\hline Content & $\begin{array}{l}\text { Positive } \\
\text { - comprehensive, useful and state-of-the art guidance; } \\
\text { - demonstrated complexity of the issues at stake; } \\
\text { - glossary useful but missing some important terms. } \\
\text { Points for improvement } \\
\text { - maybe too technical and complex for some users; } \\
\text { - stakeholder feedback from other countries not very useful; } \\
\text { - food handbook would benefit from worked examples; } \\
\text { - strategies; }\end{array}$ \\
\hline Scope & $\begin{array}{l}\text { Positive } \\
\text { • covered important areas of interest. }\end{array}$ \\
\hline $\begin{array}{l}\text { Usefulness of } \\
\text { various tools }\end{array}$ & $\begin{array}{l}\text { Positive } \\
\text { - datasheets provide a lot of general information; } \\
\text { - very interesting and useful; } \\
\text { - colour-coded selection tables in the handbook for food production systems are a useful tool } \\
\text { for constructing a management strategy. } \\
\text { Points for improvement } \\
\text { - the inhabited areas handbook would benefit from adopting colour-coded selection tables; } \\
\text { - decision trees did not reflect the complexity of the real situation (e.g. response would } \\
\text { depend on whether it was the first or second year after deposition). }\end{array}$ \\
\hline $\begin{array}{l}\text { Suitability for } \\
\text { customisation }\end{array}$ & Yes \\
\hline
\end{tabular}

The following key improvements to the handbook for inhabited areas were agreed:

- Re-structuring the handbook to make navigation easier.

- Producing a "route map" or "quick guide" to aid navigation.

- Producing a separate handbook on drinking water supplies.

- Re-designing the decision aiding framework to include colour-coded and greyscale selection tables.

All of these improvements have been implemented in version 2 of the handbooks (Nisbet et al., 2009; in prep.). 


\subsection{Feedback on the participatory approach involving stakeholders in Denmark}

Stakeholder engagement is currently not used as part of the decision-making process in Denmark. However, there were no problems in identifying a government department to drive and support the process and a co-ordinator to identify and engage the stakeholders. Ten stakeholders took part including three from non-government organisations. They expressed their clear interest in participating in the process. There was willingness from the stakeholders to openly discuss issues arising in connection with contamination of the foodchain. The stakeholders were interested in exploring the handbook for food production systems as a tool for assisting in the selection of management strategies. However, it was felt that the handbook is very large and familiarization with its content would require considerable effort. Therefore, customisation of the handbook would not be carried out in Denmark, although there are plans to integrate some parts into the Danish preparedness system. A final meeting concluded that the group would continue to work together, and also develop strategies in connection with exercises. However, the direct role of stakeholders in decision making would be limited, as the authorities would essentially make the decisions. Cross-border communication was highlighted as an important issue, and dialogue with a network of other European countries to share viewpoints would be desirable.

\subsection{Feedback on the participatory approach involving stakeholders in Slovakia}

Stakeholder engagement is currently not used as part of the decision-making process in Slovakia. Nevertheless, a seminar on "Recovery management following a radiological incident" took place in October 2009 with eighteen stakeholders. The seminar focused on the development and/or customisation of the inhabited areas and food production handbooks. This and previous experiences have shown that stakeholders are able to work together, to communicate problems and to absorb newcomers to the working groups. Facilitated scenario-based workshops using customised operational tools such as RODOS (Ehrhardt and Weis, 2000) and WebHIPRE (Hämäläinen and Mustajoki, 1998) makes the work with stakeholders more efficient, focussing on potential problems and practical solutions. There was agreement on the need to continue the stakeholder participatory process and a willingness to organise annual workshops to share experiences, to identify gaps and improve preparedness.

The experience in Slovakia confirmed that the handbooks could be used as a preparatory tool, under non-crisis conditions, to engage stakeholders and to 
develop local and regional plans. It was felt that the handbooks can also be applied as part of the decision-aiding process to develop a recovery strategy following an incident. In addition, the handbooks are useful for training purposes and during emergency exercises.

The stakeholders hope that the handbooks will be given the status of official national documents and so form the basis of their use by the wider community of specialists and organizations involved in emergency preparedness. It has already been possible to include the entire handbook or relevant sections of these in some off-site emergency plans. Work on customising the handbooks will continue within a national project funded by Slovak Nuclear Regulatory Authority (20092011). It is expected that the handbooks will then be established as National Recovery Guidance in Slovakia.

\section{Conclusions}

Demonstration activities based on the application of handbooks for food production systems and inhabited areas in emergency centres concluded that the handbooks were useful for the purposes of contingency planning and accident management but to realise their full potential they should be customised at national, regional and local levels. Feedback on the content of the handbooks was positive with constructive criticism given on how to improve their navigation, structure and format. A need for glossaries and quick guides were identified. For the handbook on food production systems, there were also requests for the inclusion of worked examples, checklists for planning in advance of an incident and the provision of more information on monitoring and measurement strategies. Feedback from the demonstrations also recommended that the drinking water section of the inhabited areas handbook be made into a stand-alone document. All of the key improvements highlighted during the Demonstrations were taken into account and included in version 2 of the handbooks.

The additional demonstrations that took place in Denmark and Slovakia to investigate the appropriateness and applicability of a stakeholder participatory process when applying the handbooks were also successful. Stakeholder engagement is currently not used as part of decision-making processes in Denmark or Slovakia. Nevertheless, a wide range of government and non-government organisations took part in the participatory process using the handbook as a tool for dialogue and debate. They expressed their willingness to discuss the issues at stake from contamination of food production systems and inhabited areas and gave a clear commitment to continue the process. 
Acknowledgements. Work on the handbooks received partial financial support from the European Commission Sixth Framework Programme (Nuclear Fission/Radiation Protection) under the EURANOS integrated project: European approach to nuclear and radiological emergency management and rehabilitation strategies (Contract No: FI6R-CT-2004-508843).

\section{REFERENCES}

Brown J., Mortimer K., Andersson K., Duranova T., Mrskov A. Hänninen R., Ikäheimonen T., Kirchner G., Bertsch V., Gallay F., Reales N. (2007) Generic Handbook for Assisting in the Management of Contaminated Inhabited Areas in Europe Following a Radiological Emergency. EURANOS(CAT1)-TN(07)-02. Available at http://www.euranos.fzk.de.

Ehrhardt J., Weis A. (Eds), RODOS: Decision Support System for Off-site Nuclear Emergency Management in Europe. European Commission, Brussels, Report EUR 19144, 2000.

Hämäläinen R.P., Mustajoki J. (1998) Web-HIPRE- Java Applet for Value Tree and AHP Analysis, Computer software, Systems Analysis Laboratory, Helsinki University of Technology.

Nisbet A.F., Brown J., Rochford H., Cabianca T., Jones A., Andersson K.G., Duranova T., Mrskov A., Hänninen R., Ikäheimonen T., Kirchner G., Bertsch V., Gallay F., Reales N. (in prep.). Generic Handbook for Assisting in the Management of Contaminated Inhabited Areas in Europe Following a Radiological Emergency v2.

Nisbet A.F., Jones A., Turcanu C., Camps J., Andersson K.G., Hanninen R., Rantavaara A., Solatie D., Kostiainen E., Jullien T., Pupin V., Ollagnon H., Papachristodoulou C., Ioannides K., Oughton D. (2009) Generic Handbook for Assisting in the Management of Contaminated Food Production Systems in Europe following a radiological emergency v2. EURANOS(CAT1)TN(09)-01. Available at http://www.euranos.fzk.de.

Nisbet A.F., Rice H., Jones A., Jullien T., Pupin V., Ollagnon H., Hardeman F., Carlé B., Turcanu C., Papachristodoulou C., Ioannides K., Hänninen R., Rantavaara A., Solatie D., Kostiainen E., Oughton D. (2006) Generic Handbook for Assisting in the Management of Contaminated Food Productions Systems in Europe following a Radiological Emergency, EURANOS(CAT1)TN(06)-06. Available at http://www.euranos.fzk.de. 